\title{
Seabirds as guides for fisheries management: European shag Phalacrocorax aristotelis diet as indicator of saithe Pollachius virens recruitment
}

\author{
Svein-Håkon Lorentsen ${ }^{1, *}$, Tycho Anker-Nilssen $^{1}$, Kjell Einar Erikstad $^{2,3}$ \\ ${ }^{1}$ Norwegian Institute for Nature Research, 7485 Trondheim, Norway \\ ${ }^{2}$ Norwegian Institute for Nature Research, FRAM - High North Research Centre on Climate and the Environment, \\ 9296 Tromsø, Norway \\ ${ }^{3}$ Centre for Conservation Biology, Department of Biology, Norwegian University of Science and Technology, \\ 7049 Trondheim, Norway
}

\begin{abstract}
In fisheries management, assessing year-class strength and recruitment to commercial stocks is essential, but can be difficult to do for fish species where the young stages are inaccessible to ship-based surveys. This is true for the northeast Arctic saithe Pollachius virens, where the juveniles spend their first years in coastal kelp forests and therefore cannot be assessed before they enter the pelagic stock at 3 yr of age. However, as top predators in marine ecosystems, coastal seabirds might prey on the same cohort 2-3 yr earlier. Long-term studies of European shag Phalacrocorax aristotelis at a colony in central Norway have revealed strong links between the birds' breeding performance and the availability of 0 and $1 \mathrm{yr}$ old saithe in their diet. Following this, we wanted to explore if shag diet can be used as an early indicator of saithe recruitment by comparing it with abundance indices obtained by fisheries research. Our results indicate that the occurrence of $0 \mathrm{yr}$ old saithe in the shag diet is a poor predictor of saithe recruitment $3 \mathrm{yr}$ later. However, both the pre- and post-hatch biomass and the number and frequency of occurrence of $1 \mathrm{yr}$ old saithe show a strong positive relationship with indices obtained from scientific surveys 2 yr later, indicating that shag diet can be used as an early and reasonably reliable predictor of saithe recruitment. We suggest implementing the occurrence of $1 \mathrm{yr}$ old saithe in the shag diet as a supplementary tool for an adaptive management of the fisheries on young saithe.
\end{abstract}

KEY WORDS: Phalacrocorax aristotelis · Central Norway · Diet · Fish stock recruitment indicator · Pollachius virens

\section{INTRODUCTION}

During the last few decades, fisheries management has experienced a shifting focus, from managing targeted species to a much wider focus on ecosystems and the impact of fisheries on these ecosystems, so called ecosystem-based fisheries management (EBFM) (e.g. Link 2002, Pikitch et al. 2004, Smith et al. 2007). Two of the overall aims of EBFM are to (1) sustain healthy marine ecosystems and their fisheries,

${ }^{*}$ Corresponding author: shl@nina.no and in particular avoid degradation of ecosystems, and (2) generate knowledge of ecosystem processes so that the consequences of human actions can be understood and quantified (Pikitch et al. 2004). Following this, and in order to ensure that the biomass removed by fisheries in an ecosystem does not exceed the total amount of system productivity after accounting for the requirements of all ecosystem components, monitoring of indicators of environmental quality and system status is essential (Link 2002, Pikitch et al. 2004).

(C) The authors 2018. Open Access under Creative Commons by Attribution Licence. Use, distribution and reproduction are unrestricted. Authors and original publication must be credited. 
In fisheries management, monitoring pelagic fish populations is performed using research vessels and scientific trawl surveys. While such monitoring is needed to assess the recruitment and adult stock size of the commercially targeted species, it is often time consuming and expensive to carry out. Furthermore, for fish species that spend most of their immature life in shallow waters, trawl surveys are limited by the inaccessibility of these areas to large vessels. Even though these fish species may be an important target for commercial fisheries, they cannot be surveyed properly until the young re-enter the open seas. Consequently, fisheries quotas may not be set with sufficient precision before fishing of sub-adult cohorts is initiated. When the nursery grounds of fish are inaccessible to research vessels, seabirds might be used as a complementary tool to assess the strength of young cohorts long before they recruit to the population targeted by the fisheries.

As top predators in marine ecosystems, many seabirds prey on small fish or young age-classes of larger fish. Consequently, they are often regarded as good indicators of fish abundance (e.g. Cairns 1987 , Furness \& Camphuysen 1997, Piatt et al. 2007a,b, Wanless et al. 2007, Einoder 2009, Horn \& Whitcombe 2015, but see Harding et al. 2007, Grémillet \& Charmantier 2010) and might be used as indicators of the environmental quality of marine ecosystems (cf. Link 2002, Pikitch et al. 2004). For instance, the relative frequencies of different prey types taken by breeding seabirds are likely to change in accordance with the availability of these prey within the birds' foraging ranges around the breeding site, suggesting that their diets can act as indicators of fish abundance (e.g. Einoder 2009, Velarde et al. 2015). Furthermore, for seabirds that prey on young fish, it might be expected that the occurrence of the different age groups in their diet will be correlated to the size of the cohorts that later recruit to the adult population. If so, these seabirds can be used to derive early estimates of the future recruitment to mature populations of fish.

The European shag Phalacrocorax aristotelis (hereafter shag) is one of the seabird species that prey on young fish that are usually unavailable to research vessels. It may thus have the potential to act as an early predictor of recruitment to the adult stock of the same fish. The shag is a coastal, pursuit-diving seabird whose staple prey in breeding colonies in the eastern Norwegian Sea is northeast Arctic saithe Pollachius virens (hereafter saithe) (Barrett et al. 1990, Barrett 1991, Anker-Nilssen 2010). For example, at Sklinna, a colony in central Norway, saithe com- prised $73 \%$ (range $62-89 \%$ ) of the biomass of the shag diet during 2007-2016 (Hillersøy \& Lorentsen 2012, S.H. Lorentsen unpubl.). Furthermore, both the timing of breeding and reproductive success of these shags have proven to be closely linked to variation in abundance of this prey (e.g. Bustnes et al. 2013, Lorentsen et al. 2015), emphasizing their potential as an indicator of fish abundance. This saithe stock spawns in pelagic waters in the eastern part of the Norwegian Sea in late winter (peaking in February). The young fish move into the kelp (Laminaria spp.) forest in shallow waters along the Norwegian coast during their first summer, stay there until they recruit to the pelagic stock at 3 yr old (Hislop et al. 2015, Mehl 2015), and become sexually mature at the age of $4-6$ yr.

Whereas the fisheries-based assessments of saithe recruitment are not possible until the young fish recruit to the pelagic stock, the spatial and temporal overlap between the nursery areas of 0-2 yr old saithe (e.g. Mehl 2015) and the feeding grounds of shags (S.H. Lorentsen unpubl.) suggest that shags may be good samplers of the abundance of young saithe (cf. Barrett 1991, Anker-Nilssen 2005, Bustnes et al. 2013, Lorentsen et al. 2015). In Norway, the saithe fishery lands about $162000 \mathrm{t}$ annually (mean for the period 1960-2013), with a monetary value (2012) of about 1 billion NOK (ca. 118 million Euro in 2016) (Mehl 2015). Between 18 and $60 \%$ (mean $41 \%$ ) were landings of $4 \mathrm{yr}$ old saithe in central Norway (The Norwegian Fishermen's Sales Organization pers. comm.). Thus, catches of young fish constitute a very significant proportion of the total landings, and are therefore likely to influence future spawning populations. Since fisheries researchers therefore have to base both their stock recruitment indices and recommendations for next year's fisheries quotas on fisheries survey data for the same cohorts collected at the time they are harvested for the first time, the quotas will be less able to account for variation in recruitment between years. Thus, also taking into consideration early indications for recruitment from the relative occurrence of younger cohorts in the diet of seabirds may provide useful guidance when aiming to balance the fisheries on older age groups in relation to recruitment variability.

In this paper, we explored whether shag diet information can be used as an early indicator of the later recruitment to the pelagic saithe stock. In particular, we explored how well age-class estimates of 0 and 1 yr old saithe, the preferred age groups in the shag diet, correlate with the recruitment of $3 \mathrm{yr}$ 
old saithe to the pelagic population as assessed from scientific trawl survey data sampled 2-3 yr later. As the shags' diet preferences might change with breeding stage and the increasing demands of their nestlings, we analysed diet data from the pre- and post-hatch period separately. This is because the pellets collected pre-hatch represent the food needed to sustain the adults, whereas the pellets collected later also represent the food intended for the chicks. Thus, even though shags feed their chicks regurgitated food, it cannot be ruled out that the shag diet, especially when the chicks are small, might shift to smaller fish than those taken in the pre-hatch period.

\section{MATERIALS AND METHODS}

\section{Shag diet data}

Shag diet samples were collected at Sklinna $\left(65^{\circ} 13^{\prime} \mathrm{N}, 10^{\circ} 58^{\prime} \mathrm{E}\right)$, a small archipelago situated $\sim 20 \mathrm{~km}$ off the mainland coast of Nord-Trøndelag in central Norway. Throughout most of the breeding season, normally between ca. 1 June and 17 July, 20-25 freshly regurgitated pellets containing undigested fish remains such as otoliths and bone fragments were collected in the colony every fifth day. During the years 2007-2015, we collected a mean of 159 (range 76-228) pellets, of which a mean of 142 (range 71-206) pellets contained saithe remains. The treatment of the pellets is described in Hillersøy \& Lorentsen (2012). In short, we digested the soft parts in a saturated solution of biological washing powder (Bio-tex ${ }^{\circledR}$ ) kept at $50^{\circ} \mathrm{C}$ in an oven for $1-2 \mathrm{~d}$. Hard parts, mainly fish otoliths and bones, were then removed and the otoliths were sorted in pairs based on size, matching appearance and/or extent of erosion (wear) before they were identified to the lowest possible taxonomic level using descriptions in Härkönen (1986) and a reference collection. The length and width of each otolith were measured to the nearest $0.1 \mathrm{~mm}$ using a binocular microscope and $\mathrm{mm}$ paper (cf. Hillersøy \& Lorentsen 2012). Individual fish length and body mass were calculated using otolith length or width, and the equations provided by Jobling \& Breiby (1986) for saithe otoliths from $0 \mathrm{yr}$ old (first year of life) fish, and Härkönen (1986) for $1 \mathrm{yr}$ and older saithe.

In order to determine total saithe biomass per pellet, we first determined the minimum number of individual fish represented in each pellet. This was obtained by counting the number of individual oto- liths after they had been paired (a paired sample of otoliths counts as 1 fish). The biomass per pellet was then calculated as the summed mass of all individuals found in the pellet. Diet data from the pre- and post-hatch periods were separated at the population level by the annual median hatching date (included in the pre-hatch group) of the year in question and analysed independently. The frequencies of otoliths of 0 and $1 \mathrm{yr}$ old saithe were obtained by counting the number of pellets with the respective otolith groups, and dividing by the total number of otoliths for the specific period. Median hatching date was obtained from 52-56 control nests (mean 54) that were checked every fifth day throughout the breeding seasons of 2007-2014.

\section{Fisheries research data on saithe recruitment}

Data on the variation in abundance of young northeast Arctic (NEA) saithe were extracted from the latest reports from the Institute of Marine Research (IMR, www.imr.no), and the International Council for the Exploration of the Sea (ICES) Arctic Fisheries Working Group (ICES 2016) with permission from ICES. These data were derived from an extended survivor's analysis assessment of the NEA saithe stock based on age-specific data on catch numbers, weight and maturity and a fixed natural mortality and tuned by catch per unit effort data from trawl fisheries and indices from an acoustic survey (ICES 2016). Since these abundance estimates on recruitment represented saithe aged $3 \mathrm{yr}$ old, our data from the shag diet samples could only be compared to IMR/ICES estimates from 2009 (for saithe being $1 \mathrm{yr}$ old in 2007, i.e. 3 yr old in 2009) or 2010 (for saithe being 0 yr old in 2007, 3 yr old in 2010) and onwards. This inherited lag in the use of the IMR/ICES recruitment data in the analyses restricted the number of comparable datasets to 7 for 0 yr old saithe and 8 for 1 yr old saithe.

\section{Statistical analyses}

We used ANOVA to test for annual variation in abundance estimates and the biomass of 0 and $1 \mathrm{yr}$ old saithe, and simple regression analysis to test for relationships between 0 and $1 \mathrm{yr}$ old saithe from shag pellets and IMR/ICES abundance indices of recruitment of 3 yr old saithe. Test results with $p<0.05$ were considered significant. 


\section{RESULTS}

We found large inter-annual variation in both the IMR/ICES abundance estimates of recruitment of 3 yr old saithe and the biomass of 0 and 1 yr old saithe in the shag diet $\left(\mathrm{ANOVA}, F_{7,1163}=9.00, \mathrm{p}<0.001\right.$, and $F_{7,1163}=20.67, \mathrm{p}<0.001$ for 0 and 1 yr old saithe, respectively; Fig. 1).

The relationships between the pre- and post-hatch annual means of 0 yr biomass, the mean number and the frequency of occurrence of $0 \mathrm{yr}$ old saithe per pellet and the IMR/ICES abundance estimates tended to be positive (Fig. 2). Nevertheless, except for the frequency of occurrence of $0 \mathrm{yr}$ old saithe pre-hatch, none of these relationships were significant (prehatch biomass: $\mathrm{r}^{2}=0.31, \mathrm{p}=0.191$; pre-hatch number of saithe: $r^{2}=0.16, p=0.372$; pre-hatch frequency of occurrence: $r^{2}=0.70, p=0.020$; post-hatch biomass:

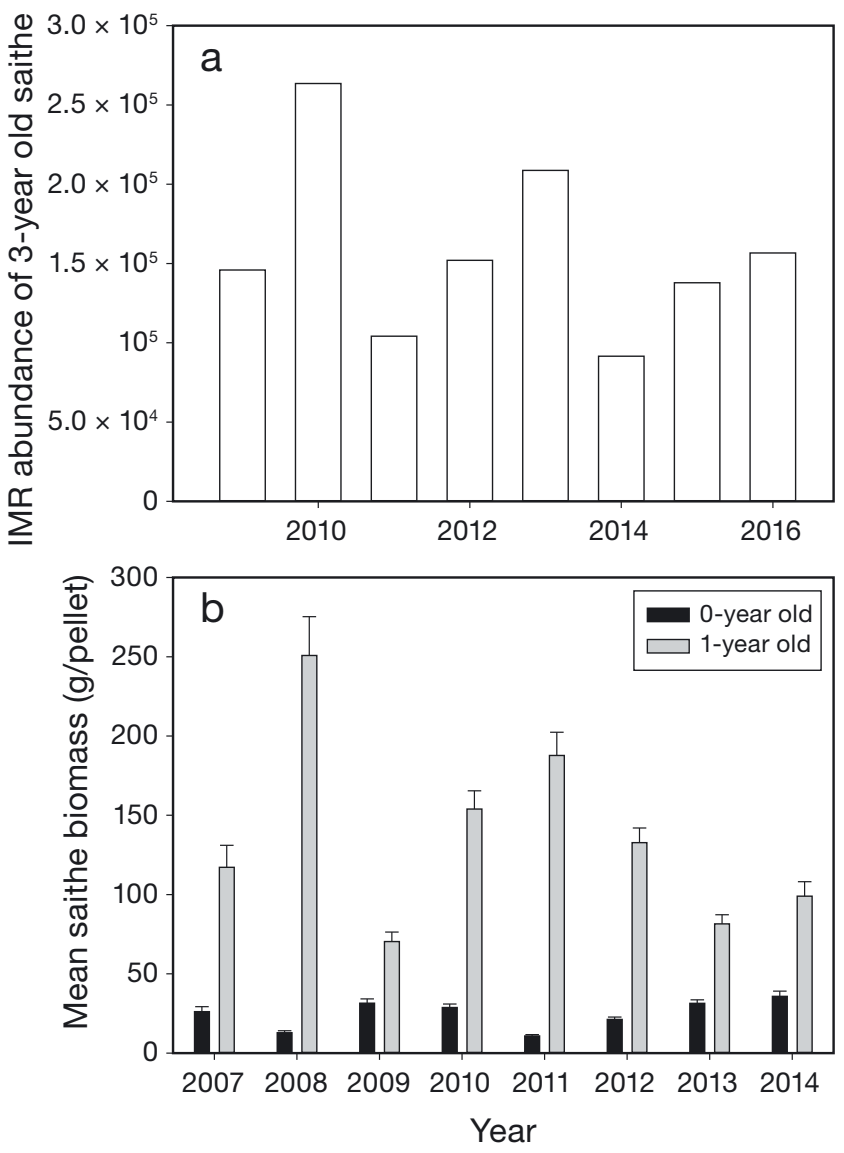

Fig. 1. (a) Annual variation in Institute of Marine Research / International Council for the Exploration of the Sea (IMR/ ICES) abundance estimates of saithe recruits at the age of $3 \mathrm{yr}$ and (b) annual variation in biomass of 0 and $1 \mathrm{yr}$ old saithe $( \pm \mathrm{SE})$ in the shag diet at Sklinna. The panels can be compared directly given that 0 and 1 yr old saithe in the lower panel in 2007 became 3 yr olds in 2010 and 2009, respectively $\mathrm{r}^{2}=0.28, \mathrm{p}=0.222$; post-hatch number of saithe: $\mathrm{r}^{2}=$ $0.32, p=0.182$; post-hatch frequency of occurrence: $\left.\mathrm{r}^{2}=0.10, \mathrm{p}=0.494\right)$.

The corresponding relationships for $1 \mathrm{yr}$ old fish, however, were seemingly strong and significant, and increased from pre- to post-hatch (pre-hatch biomass: $\mathrm{r}^{2}=0.60, \mathrm{p}=0.024$; pre-hatch number of saithe: $\mathrm{r}^{2}=0.75, \mathrm{p}=0.005$; pre-hatch frequency of occurrence: $\mathrm{r}^{2}=0.52, \mathrm{p}=0.043$; post-hatch biomass: $\mathrm{r}^{2}=$ $0.81, p=0.002$; post-hatch number of saithe: $\mathrm{r}^{2}=0.86$, $\mathrm{p}<0.001$; post-hatch frequency of occurrence: $\mathrm{r}^{2}=$ $0.82, p=0.002$ ) (Fig. 3). Using a pooled sample of pellet data for the whole breeding season demonstrated the robustness of the relationship between samples of $1 \mathrm{yr}$ old saithe and lagged IMR/ICES abundance estimates (biomass: $\mathrm{r}^{2}=0.72, \mathrm{p}=0.008$; number of saithe: $r^{2}=0.81, p=0.002$; frequency of occurrence: $\left.r^{2}=0.76, p=0.003\right)$.

\section{DISCUSSION}

There are a number of methodological considerations when using otoliths from seabird regurgitates in diet studies. One of the main issues addressed is otolith wear and tear during digestion, and otolith recovery in regurgitated pellets (e.g. Jobling \& Breiby 1986, Johnstone et al. 1990, Zijlstra \& van Eerden 1995, Carss et al. 1997, Barrett et al. 2007). Generally, studies on captive shags show that otoliths from e.g. gadoid fishes are recovered in much higher frequencies that otoliths from many other fish species in seabird diets, including sandeels (Ammodytes spp.), sprat Sprattus sprattus and herring Clupea harengus (Johnstone et al. 1990). However, Zijlstra \& van Eerden (1995) suggested that digestion in birds in captivity and in the wild appears to be different, and that experiment-induced stress causes severe otolith wear, making such studies inapplicable for field studies. Cormorants and shags, on average, regurgitate once a day (e.g. Johnstone et al. 1990, Zijlstra \& van Eerden 1995), but this might vary over time and among individuals and may be related to prey type and abundance (e.g. Johnstone et al. 1990). Nevertheless, estimates of fish intake from pellets seem to correspond very well with the bird's energetic demands (Voslamber 1988, Dirksen et al. 1995 cited by Zijlstra \& van Eerden 1995), suggesting that otolith wear and tear in wild birds might be less than anticipated from studies on captive birds (Zijlstra \& van Eerden 1995, and references therein). Although diet studies, and biomass estimates, based on regurgitated pellets should be evaluated with care (cf. 
Carss et al. 1997, Barrett et al. 2007), we assume that the approach is applicable to our study population because (1) we used only otoliths from saithe, a gadoid fish where otolith wear is less than for most other fish species (cf. Jobling \& Breiby 1986, Johnstone et al. 1990), and (2) we expect little inter-

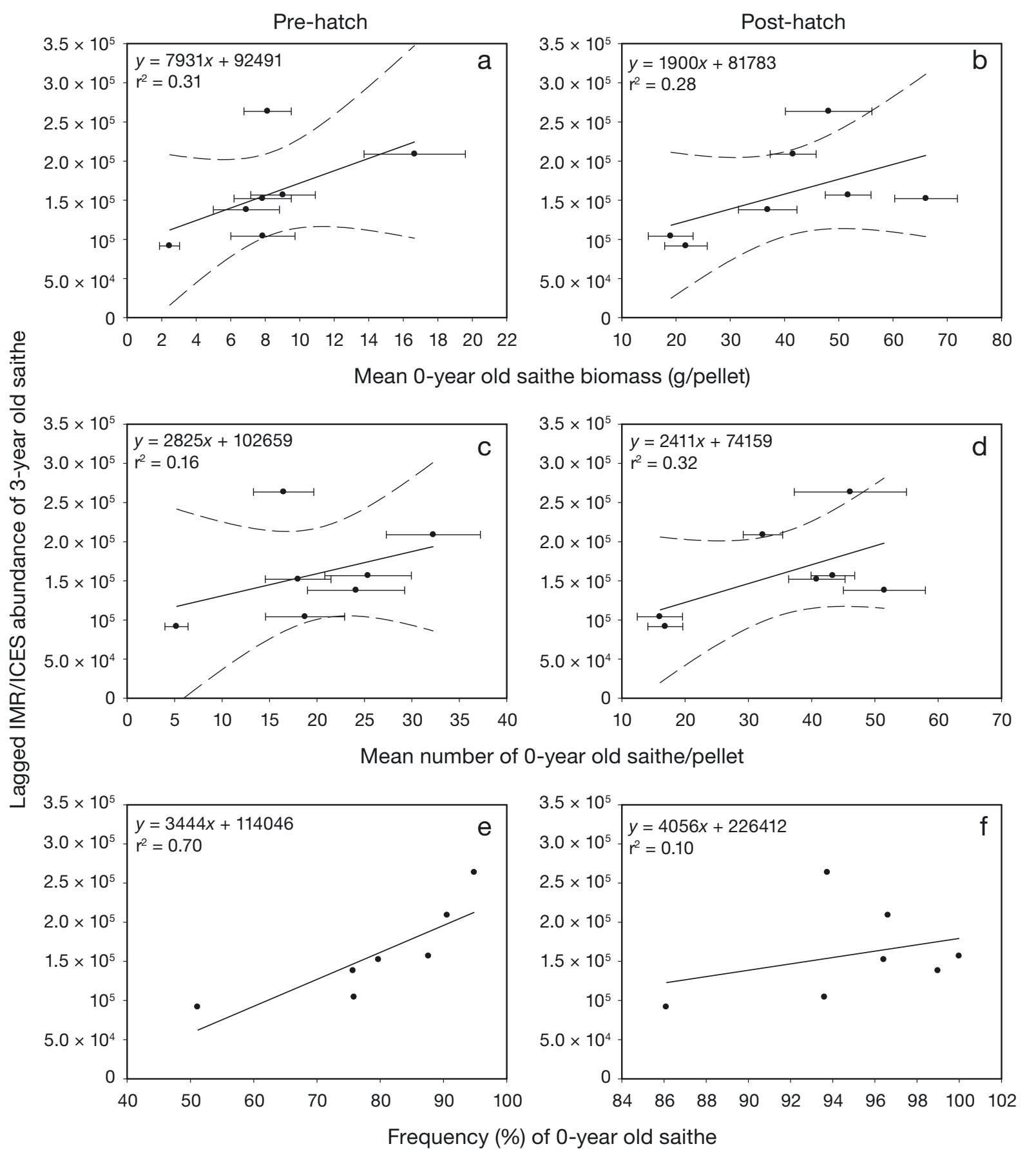

Fig. 2. Relationship between IMR/ICES abundance estimates of saithe recruits at the age of 3 yr and (a,b) the mean biomass, $(c, d)$ numbers and $(e, f)$ frequency of occurrence of $0 \mathrm{yr}$ old saithe in the shag diet at Sklinna in the pre-hatch period (left column), and the post-hatch period (right column). Horizontal bars indicate \pm SE and dashed lines the $95 \%$ confidence interval.

The regression equation and its $\mathrm{r}^{2}$-value are indicated in each panel

annual variance in wear and tear of otoliths in shag pellets collected at only 1 site. Still, we assume that our estimates of pellet biomass only represent a minimum estimate.

Short-term (days to weeks) parameters, such as seabird diet composition, are suggested to be most 


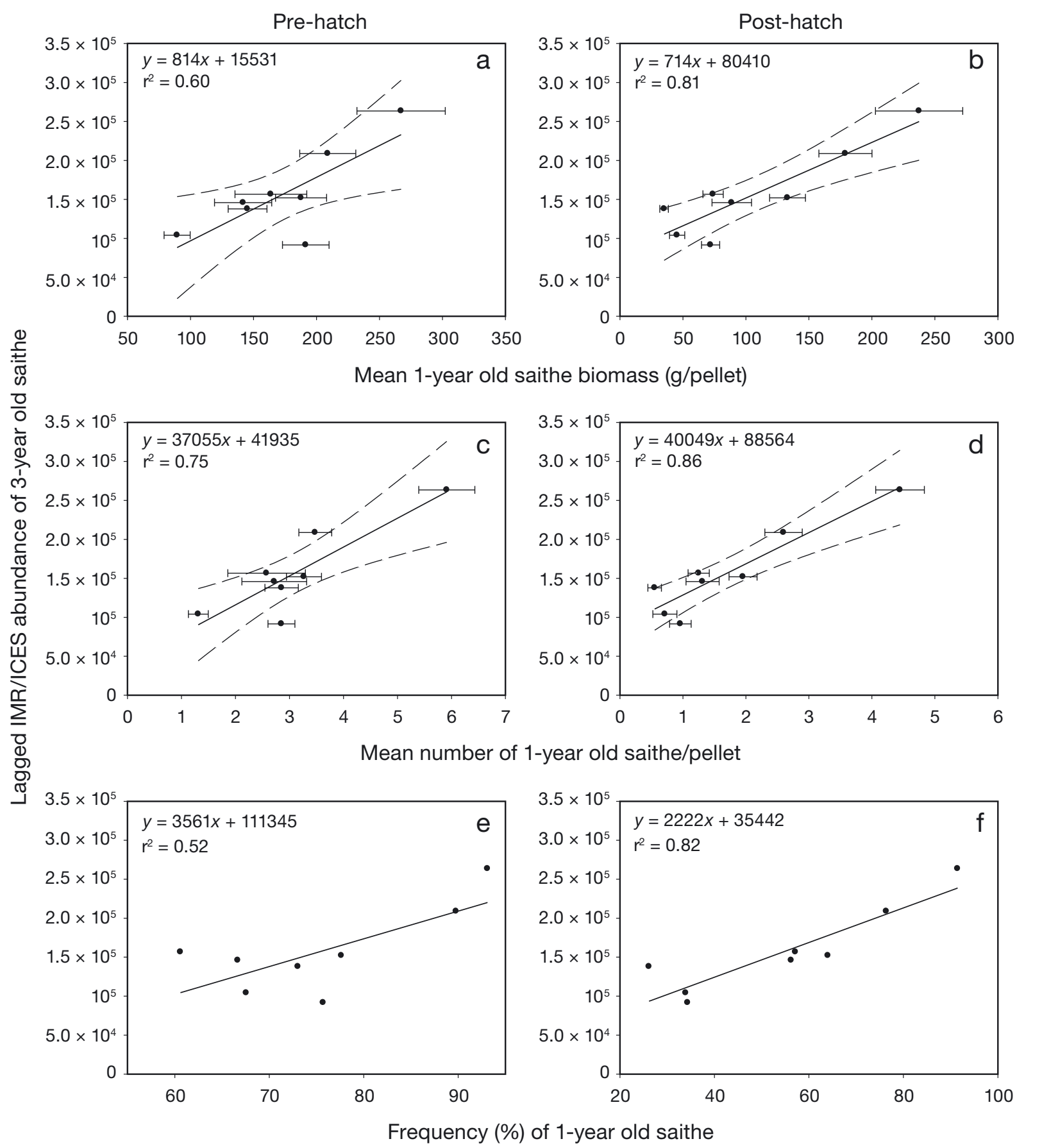

Fig. 3. As in Fig. 2, but for 1 yr old saithe

useful when seeking information on prey assemblages or the age-structure of fish populations (e.g. Montevecchi 1993), and generalist seabirds, like the shag, are likely to reflect prey availability the best as they often target the most abundant prey species (e.g. Montevecchi et al. 1987, Furness \& Tasker 2000). Nevertheless, an important factor in the use of dietary composition of seabirds to monitor changes in prey availability is the behavioural plasticity and reaction norms of predators and prey (Grémillet \& Charmantier 2010), and the uncertainty in the functional relationship between prey density and diet (e.g. Piatt et al. 2007b). It is suggested that the latter can be studied by measuring prey abundance through ship-based methods (e.g. Piatt et al. 2007b), but this is extremely difficult for seabird-prey like juvenile saithe that spend their first years in dense kelp forests. Until this obstacle is solved the causal 
relationships between shag diet and saithe availability can only be studied using a simple regressional approach.

Our results suggest that using the occurrence (by numbers or biomass) of $0 \mathrm{yr}$ old saithe in the shag diet as an indicator of saithe recruitment 3 yr later is, currently, not advisable. Although relationships between the frequency of $0 \mathrm{yr}$ old saithe otoliths and saithe recruitment indices were significant for the pre-hatch period, this was not the case for the posthatch period. There might be several reasons for the relatively weak relationships between 0 yr old saithe remains in the shag diet and IMR/ICES recruitment indices of $3 \mathrm{yr}$ old saithe to the pelagic population. These probably include a high and unaccounted mortality of $0 \mathrm{yr}$ old saithe during their first year in the nursery areas. For instance, Bustnes et al. (2013) showed that the occurrence of $0 \mathrm{yr}$ old saithe in the shag diet is strongly and positively correlated with the occurrence of $1 \mathrm{yr}$ old saithe the year after, suggesting that shags might track the availability of these age-groups quite well. Thus, the results suggest that the occurrence of $0 \mathrm{yr}$ old saithe in the shag diet might, in the future, be developed into a recruitment indicator. However, before this is achieved, a better understanding of e.g. mortality factors of $0 \mathrm{yr}$ olds is needed.

The strong and significant relationship between the pooled data of $1 \mathrm{yr}$ old saithe occurrence in the shag diet and the IMR/ICES recruitment indices of $3 \mathrm{yr}$ olds into the pelagic population indicates that shags might help forecast the abundance of saithe at least $2 \mathrm{yr}$ ahead of the fisheries surveys. One yr old saithe are important for the onset of breeding and clutch size for these shags (Bustnes et al. 2013, Lorentsen et al. 2015), and a strong relationship between the pre-hatch abundance indices (biomass, numbers of saithe per pellet and frequency of occurrence) and the lagged IMR/ICES abundance estimates could therefore be expected. Still, the explained variance of the corresponding relationships in the post-hatch period were even higher. Thus, even though pre-hatch relationships are significant, the results demonstrate that a sample from the posthatch period forms a better basis to refine the use of shag diet as an indicator of saithe recruitment.

Despite the multitude of studies demonstrating that seabirds might be good indicators of prey abundance (see references in the Introduction), very few have attempted to use the occurrence of juvenile fish in seabird diet to predict future fish recruitment to the spawning population. As suggested by Piatt et al. (2007a), the use of seabirds as indicators in manage- ment has to develop from a contextual relationship, providing information on conditions where humans have no direct control, to a predictive relationship, providing information on conditions over which humans have some control. Up to now only few studies on the functional, or predictive, relationships between seabirds and ecosystem properties have been published (e.g. Hatch \& Sanger 1992, Roth et al. 2007, Lyday et al. 2015, Velarde et al. 2015). In that context, the results from our study suggest there is a potential for using the post-hatch occurrence of $1 \mathrm{yr}$ old saithe in the shag diet as an early indicator of the recruitment to the pelagic and commercially harvested stock of NEA saithe. During most of the study period (2007-2013), the NEA saithe spawning population and the fisheries landings in central Norway were reduced by 48 and $52 \%$, respectively (Mehl 2015, ICES 2016, The Norwegian Fishermen's Sales Organization pers. comm.). At the same time, landings of 4 yr old saithe increased by $23 \%$, indicating it might be necessary (and profitable) to reduce the catches of immature fish. Fisheries research recruitment indices might be available too late to be used as a tool for managing the fisheries of $4 \mathrm{yr}$ old saithe. We therefore suggest it would prove useful to implement shag diet as an early predictor of saithe recruitment, as an integrated part of a more adaptive management of saithe fisheries.

Compared to fisheries research surveys, monitoring shag diet is cheap, and the results are available for a much earlier use in supporting fisheries management than current recruitment indices. Even if we still only have $8 \mathrm{yr}$ of data available for comparison with the IMR/ICES data, and use data from only 1 shag colony, the results are promising and should be refined further in the future. In this context, it is important to bear in mind that shags are generalist seabirds, whose diet is likely to be dominated by the most abundant prey species at any time (e.g. Montevecchi et al. 1987, Furness \& Tasker 2000). Changes in marine ecosystems may therefore affect the relative importance of their main prey (cf. Howells et al. 2017), and emphasize the need to continue monitoring the shag's prey diet composition to help assess its precision and value as an early recruitment index of fish stocks in the longer run.

Acknowledgements. We are indebted to all field assistants who helped collect shag regurgitates at Sklinna, to Grethe Hillersøy for analysing the samples, and to 3 anonymous referees for valuable comments on the manuscript. All work in the colony was approved by the Norwegian Environment Agency and the county governor of Nord-Trøndelag. We are 
also indebted to the Norwegian Coastal Administration for allowing us to use the Sklinna lighthouse facilities as a field station. The regurgitates were collected during fieldwork for the SEAPOP programme (www.seapop.no), which is financed by the Norwegian Ministry of Climate and Environment via the Norwegian Environment Agency, the Norwegian Ministry of Petroleum and Energy via the Norwegian Research council and the Norwegian Oil and Gas Association.

\section{LITERATURE CITED}

Anker-Nilssen T (2005) Sjøfugl og sei: predatorer og indikatorer $\mathrm{i}$ et klimaperspektiv. In: Svenning MA, Jonsson B (eds) Kystøkologi: økosystemprosesser og menneskelig aktivitet. NINA Temahefte 31. Norwegian Institute for Nature Research, Trondheim, p 33-37

Anker-Nilssen T (2010) Key-site monitoring in Røst in 2009. SEAPOP Short Report 12-2010. http://www.seapop.no/ opencms/export/sites/SEAPOP/no/filer/short-reports/ 2009/SEAPOP-Short-Report-05-2009-optimized.pdf

* Barrett RT (1991) Shags (Phalacrocorax aristotelis) as potential samplers of juvenile saithe (Pollachius virens (L.)) stocks in northern Norway. Sarsia 76:153-156

Barrett RT, Røv N, Loen J, Montevecchi WA (1990) Diets of shags Phalacrocorax aristotelis and cormorants P. carbo in Norway and possible implications for gadoid stock recruitment. Mar Ecol Prog Ser 66:205-218

Barrett RT, Camphuysen CJ, Anker-Nilssen T, Chardine JW and others (2007) Diet studies of seabirds: a review and recommendations. ICES J Mar Sci 64:1675-1691

* Bustnes JO, Anker-Nilssen T, Erikstad KE, Lorentsen SH, Systad GH (2013) Changes in the Norwegian breeding population of European shag correlate with forage fish and climate. Mar Ecol Prog Ser 489:235-244

Cairns DK (1987) Seabirds as indicators of marine food supplies. Biol Oceanogr 5:261-271

Carss DN, Bevan RM, Bonetti A, Cherubini G and others (1997) Techniques for assessing cormorant diet and food intake: towards a consensus review. Ric Biol Selvaggina 26(Suppl):197-230

Dirksen S, Boudewijn TJ, Noordhuis R, Marteijn ECL (1995) Cormorants Phalacrocorax carbos sinensis in shallow eutrophic freshwater lakes: prey choice and fish consumption in the nonbreeding period and effects of largescale fish removal. Ardea 83:167-184

Einoder LD (2009) A review of the use of seabirds as indicators in fisheries and ecosystem management. Fish Res 95: 6-13

Furness RW, Camphuysen CJ (1997) Seabirds as monitors of the marine environment. ICES J Mar Sci 54:726-737

Furness RW, Tasker ML (2000) Seabird-fishery interactions: quantifying the sensitivity of seabirds to reductions in sandeel abundance and identification of key areas for sensitive seabirds in the North Sea. Mar Ecol Prog Ser 202:253-264

Grémillet D, Charmantier A (2010) Shifts in phenotypic plasticity constrain the value of seabirds as ecological indicators of marine ecosystems. Ecol Appl 20:1498-1503

* Harding AMA, Piatt JF, Schmutz JA, Shultz MT, van Pelt TI, Kettle AB, Speckman SG (2007) Prey density and the behavioral flexibility of a marine predator: the common murre (Uria aalge). Ecology 88:2024-2033

Härkönen TJ (1986) Guide to the otoliths of the bony fishes of the northeast Atlantic. Danbiu ApS, Copenhagen
Hatch SA, Sanger GA (1992) Puffins as samplers of juvenile pollock and other forage fish in the Gulf of Alaska. Mar Ecol Prog Ser 80:1-14

Hillersøy G, Lorentsen SH (2012) Annual variation in the diet of breeding European shag (Phalacrocorax aristotelis) in Central Norway. Waterbirds 35:420-429

Hislop J, Bergstad OA, Jakobsen T, Sparholt H and others (2015) Cod fishes (Gadidae). In: Heesen HJL, Daan N, Ellis JR (eds) Fish atlas of the Celtic Sea, North Sea, and Baltic Sea. KNNV and Wageningen Academic Publishers, Wageningen, p 186-236

*Horn MH, Whitcombe CD (2015) A shallow-diving seabird predator as an indicator of prey availability in southern California waters: a longitudinal study. J Mar Syst 146: 89-98

*Howells RJ, Burthe SJ, Green JA, Harris MP and others (2017) From days to decades: short- and long-term variation in environmental conditions affect offspring diet composition of a marine top predator. Mar Ecol Prog Ser 583:227-242

ICES (International Council for the Exploration of the Sea) (2016) Report of the Arctic Fisheries Working Group (AFWG), 19-25 April 2016. ICES CM 2016/ACOM:06. ICES, Copenhagen

Jobling M, Breiby A (1986) The use and abuse of fish otoliths in studies of feeding habits of marine piscivores. Sarsia 71:265-274

Johnstone IG, Harris MP, Wanless S, Graves JA (1990) The usefulness of pellets for assessing the diet of adult shags Phalacrocorax aristotelis. Bird Study 37:5-11

Link JS (2002) What does ecosystem-based fisheries management mean? Fisheries 27:18-21

KLorentsen SH, Anker-Nilssen T, Erikstad KE, Røv N (2015) Forage fish abundance is a predictor of timing of breeding and hatching brood size in a coastal seabird. Mar Ecol Prog Ser 519:209-220

Lyday SE, Ballance LT, Field DB, Hyrenbach KD (2015) Shearwaters as ecosystem indicators: towards fisheryindependent metrics of fish abundance in the California Current. J Mar Syst 146:109-120

Mehl S (2015) Nordaustarktisk sei. In: Bakketeig IE, Gjøsæter H, Hauge M, Sunnset BH, Toft KØ (eds) Havforskningsrapporten 2015. Fisk Havet 1-2015, Institute of Marine Research, Bergen, p 184-185

Montevecchi WA (1993) Birds as indicators of change in marine prey stocks. In: Furness RW, Greenwood JJD (eds) Birds as monitors of environmental change. Chapman \& Hall, London, p 217-265

Montevecchi WA, Birt VL, Cairns DK (1987) Dietary shifts of seabirds associated with local fisheries failures. Biol Oceanogr 5:153-161

* Piatt JF, Sydeman WJ, Wiese F (2007a) Introduction: seabirds as indicators of marine ecosystems. Mar Ecol Prog Ser 352:199-204

*Piatt JF, Harding AMA, Shultz M, Speckman SG, van Pelt TI, Drew GS, Kettle AB (2007b) Seabirds as indicators of marine food supplies: Cairns revisited. Mar Ecol Prog Ser 352:221-234

*Pikitch EK, Santora C, Babcock EA, Bakun A and others (2004) Ecosystem-based fishery management. Science 305:346-347

Koth JE, Mills KL, Sydeman WJ (2007) Chinook salmon (Oncorhynchus tshawytscha) - seabird covariation off central California and possible forecasting applications. Can J Fish Aquat Sci 64:1080-1090 
Smith ADM, Fulton EJ, Hobday AJ, Smith DC, Shoulder P (2007) Scientific tools to support the practical implementation of ecosystem-based fisheries management. ICES J Mar Sci 64:633-639

Velarde E, Ezcurra E, Anderson DW (2015) Seabird diet predicts following-season commercial catch of Gulf of California Pacific sardine and northern anchovy. J Mar Syst 146:82-88

Voslamber B (1988) Visplaatskeuze, foerageerwijze en voedselkeuze van Aalscholvers Phalacrocorax carbo in

Editorial responsibility: Yves Cherel, Villiers-en-Bois, France het IJsselmeergebied in 1982. Flevobericht 286. Rijksdienst voor de IJsselmeerpolders, Lelystad

*Wanless S, Fredriksen M, Daunt F, Scott BE, Harris MP (2007) Black-legged kittiwakes as indicators of environmental change in the North Sea: evidence from longterm studies. Prog Oceanogr 72:30-38

Zijlstra M, van Eerden MR (1995) Pellet production and the use of otoliths in determining the diet of cormorants Phalacrocorax carbo sinensis: trials with captive birds. Ardea 83:123-131

Submitted: March 6, 2017; Accepted: November 29, 2017 Proofs received from author(s): December 22, 2017 